\title{
Doença de Graves: a visão do doente e impacto biopsicossocial - um relato de caso
}

Ana Cláudia Cardoso Almeida,* Luís de Pinho-Costa,* Hélder Sousa*

\section{RESUMO}

Introdução: A descrição deste caso pretende enfatizar a importância do papel do médico de família, não apenas na suspeita clínica de doença de Graves e complicações associadas, mas sobretudo na adaptação do indivíduo à vivência com a doença, dada a morbilidade psicossocial associada à proptose desfigurativa e/ou diplopia, ambas manifestações com um impacto marcado no estado funcional e bem-estar dos doentes.

Descrição do caso: Mulher de 29 anos, sem antecedentes de relevo, é diagnosticada com doença de Graves, com oftalmopatia causadora de dor retro-ocular e diplopia com impacto significativo na sua vida diária. Apesar da estabilização da função tiroideia com o tratamento instituído, verificou-se progressão bilateral da exoftalmia. Neste contexto desenvolveu um quadro de insatisfação com a sua imagem corporal, alteração da identidade (antes e após o diagnóstico) e depressão, que culminou em tentativa de suicídio por intoxicação medicamentosa.

Comentário: O médico de família deverá estar sensibilizado para o impacto negativo na saúde mental e física, nas aptidões sociais e económicas, assim como na qualidade de vida destes doentes. Neste caso, a utente não estava apenas fisicamente doente, mas também apresentava distress psicológico associado à oftalmopatia, responsáveis por um impacto severo no seu funcionamento diário.

Palavras-chave: Doença de Graves; Oftalmopatia de Graves; Qualidade de vida; Exoftalmia; Hipertiroidismo.

\section{INTRODUÇÃO}

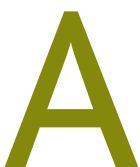

doença de Graves é a causa mais comum de hipertiroidismo persistente em adultos, a que correspondem 60 a $80 \%$ dos casos. ${ }^{1-2}$ É uma das doenças autoimunes mais frequentes, surgindo numa relação género feminino/masculino de 5-10:1, sendo a incidência estimada de dezasseis por cada 100.000 pessoas/ano no género feminino, comparativamente a três em 100.000 /ano no género masculino. ${ }^{1-4}$ Pode surgir em qualquer idade. Contudo, existem dois picos para cada género: 40-44 anos e 60-64 anos nas mulheres e 45-49 anos e 65-69 anos nos homens, com um aparecimento mais precoce de cerca de cinco anos na mulher. ${ }^{5}$

O diagnóstico precoce diminui o desenvolvimento de complicações e um tratamento adequado associase a um bom controlo da doença na maioria das situa-

*USF Fânzeres - ACeS Grande Porto II ções. ${ }^{2}$ A oftalmopatia constitui a principal manifestação extratiroideia da doença de Graves e afeta $90 \%$ dos doentes, sendo clinicamente evidente em $50 \%$ destes. ${ }^{2-}$ ${ }^{6}$ Está presente em cerca de $20-25 \%$ na altura do diagnóstico de hipertiroidismo, podendo em alguns casos tornar-se aparente apenas após o início do tratamento do hipertiroidismo. ${ }^{6}$ Apresenta tipicamente um atingimento bilateral, sendo desfigurante e incapacitante. ${ }^{4,7}$ A sua história natural pode ser muito variável, podendo manter-se estável durante muitos anos ou agravar com o tempo, de forma independente do controlo da função tiroideia e ainda numa pequena percentagem de doentes apresentar um curso com remissões e exacerbações. ${ }^{6}$ Existem alguns fatores relacionados com o aumento do risco de desenvolvimento da oftalmopatia, nomeadamente o género feminino, o tabagismo, títulos elevados de anticorpos antitiroideus, stress emocional e idade avançada (superior a 60 anos) ${ }^{8-9} \mathrm{O}$ tabagismo relaciona-se não só com o desenvolvimento da oftalmopatia, mas também com a sua gravidade. ${ }^{8}$ 
A depressão e ansiedade são patologias frequentes na população em geral, estando descrita uma prevalência aumentada no hipertiroidismo, particularmente na fase inicial da doença de Graves..$^{10-12} \mathrm{~A}$ oftalmopatia de Graves, quando presente, está associada a uma elevada morbilidade psicossocial pela proptose desfigurativa e/ou diplopia associadas, ambas manifestações com um impacto marcado no estado funcional e bem-estar dos doentes. ${ }^{7}$ De acordo com o estudo de Coulter e colaboradores, a depressão e ansiedade estão presentes, respetivamente, em $40 \%$ e $23 \%$ dos doentes com oftalmopatia de Graves..$^{13}$ Por outro lado, a existência de perturbação mental é o fator de risco mais importante para o suicídio, sendo a depressão a mais frequente. ${ }^{14}$ Os acontecimentos de vida negativos recentes, como o divórcio e a doença física, sobretudo se estiverem associados a défices funcionais ou alteração da imagem corporal, podem também aumentar o risco. ${ }^{15}$ Deste modo, a doença de Graves e as complicações associadas, sobretudo a oftalmopatia, podem afetar a saúde mental e física, as aptidões sociais e económicas, assim como a qualidade de vida dos doentes. ${ }^{4,7}$

Com o presente caso, os autores pretendem enfatizar:

- A importância do médico de família na suspeita diagnóstica precoce de doenças pouco frequentes, mas potencialmente graves, como é o caso da doença de Graves e complicações associadas;

- O papel do médico de família na adaptação do indivíduo à vivência com a doença (no presente caso sobretudo na adaptação a situações clínicas com modificação da imagem corporal, que são comuns no âmbito da medicina geral e familiar, e que interagem com a pessoa nas suas múltiplas dimensões: física, psicológica, social, familiar e laboral);

- As características dos cuidados de saúde primários, nomeadamente a acessibilidade, a continuidade dos cuidados, a visão global e holística (com a integração de aspetos psicossociais e a familiares) e os cuidados centrados na pessoa permitem, não só o acompanhamento da evolução a curto e longo prazo da vivência da doença, a adaptação à crise por ela gerada e eventos acompanhantes, mas também a gestão dos múltiplos intervenientes, tanto no que respeita aos familiares e amigos, como dos restantes profissionais de saúde envolvidos.

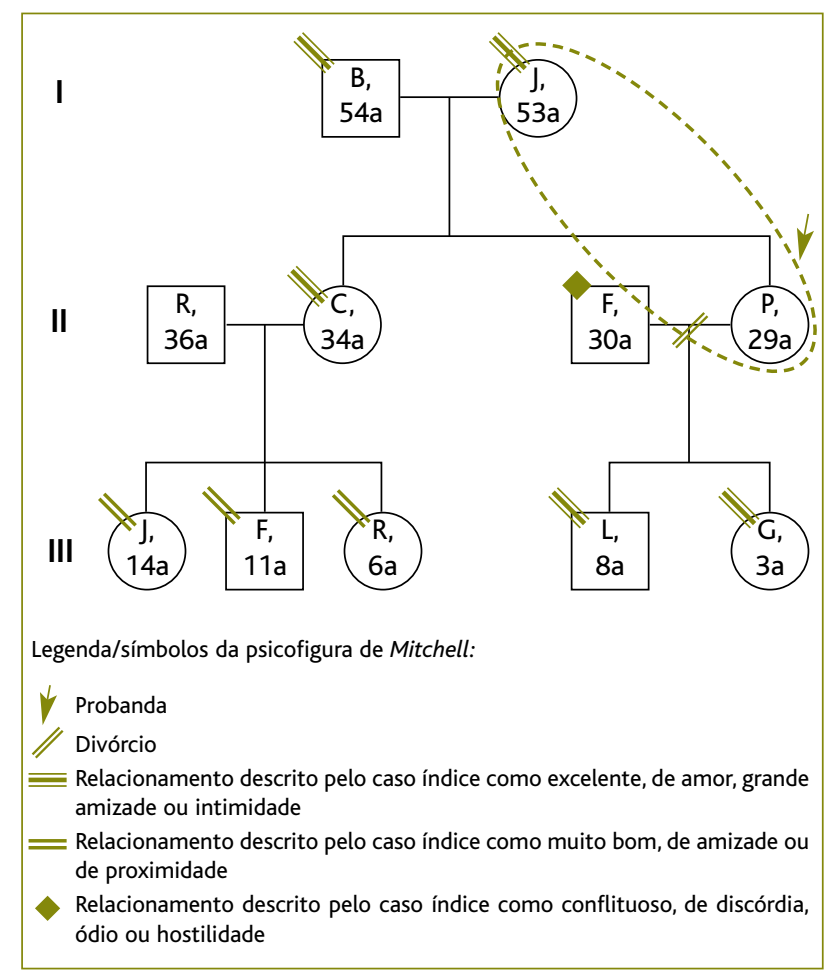

Figura 1. Genograma e psicofigura de Mitchell - Gondomar, dezembro de 2015. III 1,2,3,4,5 - saudáveis; II1 e 2 - saudáveis; II4 - doença de Graves com oftalmopatia associada e depressão reativa neste contexto; I1 - saudável; emigrado em França; II2 - antecedentes de carcinoma do pulmão diagnosticado em 2000 e submetida a pneumectomia no mesmo ano; patologia depressiva desde 2005.

\section{DESCRIÇÃO DO CASO}

Apresenta-se o caso de uma mulher de 29 anos, caucasiana, com nove anos de escolaridade, cabeleireira de profissão. Pertencia a uma família nuclear na fase IV do ciclo de Duvall até se ter divorciado no desenrolar dos eventos descritos abaixo. Atualmente pertence a uma família monoparental, classe social média de acordo com a classificação de Graffar, com médio risco de disfunção na escala de risco de Segovia-Dreyer e que não pontua na Escala de risco Garcia-Gonzalez - genograma e psicofigura de Mitchell na figura 1. É a segunda numa fratria de dois, sem padrões de repetição intergeracional de patologias, nomeadamente de patologia autoimune ou tiroideia. Sem antecedentes patológicos pessoais ou familiares de relevo, nomeadamente sem antecedentes de patologia psiquiátrica. Menarca aos 12 anos de idade, com ciclos menstruais regulares, com cerca de quatro dias de duração, sem antecedentes 


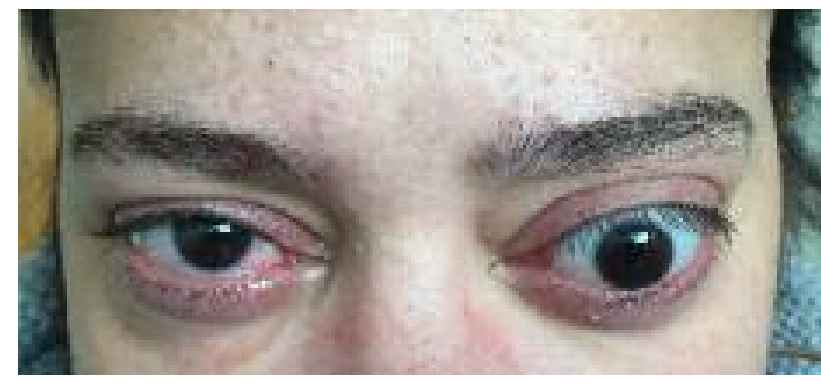

Figura 2. Oftalmopatia de Graves assimétrica.

ginecológicos de relevo, nomeadamente de meno ou metrorragias. História de duas gestações e dois partos de termo, sem complicações associadas durante a gravidez ou no puerpério. Sem antecedentes de infertilidade. Fumadora de cerca de 15 cigarros por dia, desde há 10 anos (7,5 UMA), negando outros consumos toxifílicos, nomeadamente álcool ou drogas ilícitas. Sem medicação habitual.

Em janeiro de 2014 foi observada em consultório médico privado por queixas oculares, que a doente descrevia como sensação de olhos inchados (sic). O quadro foi interpretado como alergia ocular e medicada em conformidade. Em outubro do mesmo ano recorreu a uma consulta não programada na Unidade de Saúde Familiar (USF) dos autores, por diarreia de predomínio pós-prandial, com cerca de quatro semanas de evolução, sem muco ou sangue, com perda ponderal associada. A doente referia que havia perdido cerca de $10 \mathrm{~kg}$ no último mês, apesar de manter o apetite e aporte alimentar habitual e não ter aumentado a sua atividade física. Negava palpitações, intolerância ao calor/frio ou irregularidades menstruais. Ao exame objetivo, a exoftalmia bilateral era evidente (Figura 2), associada a proptose e edema periorbitário. Adicionalmente, a doente referia dor retro-ocular e diplopia de início recente, que relacionava com alergia ocular diagnosticada no início do ano, mas que afetavam de forma significativa as suas atividades de vida diária e impossibilitavam o desempenho das suas atividades laborais como cabeleireira. À palpação da tiroide, esta apresentava-se não dolorosa, com dimensões aumentadas. Perante a anamnese e exame objetivo foi solicitado o doseamento dos níveis de T4 livre e de TSH, assim como os anticorpos antitiroideus, cujos resultados, obtidos cerca de cinco dias depois da consulta, revela- ram níveis de TSH indetetáveis, T4 livre aumentado e autoanticorpos antirrecetores de TSH positivos, sugestivos de doença de Graves. Foi explicada à doente a patologia, manifestações clínicas e tratamento disponível para iniciar ao nível dos cuidados de saúde primários, até à data da consulta hospitalar. Foi ainda esclarecida quanto à etiologia dos sintomas oculares, que não estavam relacionados com a alergia, mas constituíam uma manifestação ocular da doença de Graves. A doente mostrava-se ansiosa quanto à evolução dos sinais e sintomas oculares, dado o seu impacto funcional e verbalizava vontade de retomar rapidamente as suas atividades laborais. Foram explorados e valorizados os sintomas, emoções, sentimentos e preocupações da doente e tentou-se gerir as suas expectativas quanto à evolução dos sintomas oculares; foi-lhe explicado que seria devidamente orientada para consulta de especialidade e que, mesmo no caso de ter indicação para tratamento cirúrgico, inicialmente seria sempre necessário um período de espera pela possibilidade de estabilização ou remissão espontânea da oftalmopatia. Foi acordado um plano terapêutico, em que após decisão partilhada com a doente se optou pela iniciação de medicação com antitiroideus de síntese (tiamazol 10mg), carbómero para lubrificação ocular e penso ocular. Foi também dada indicação para repetição do doseamento de TSH e T4 livre em quatro semanas para ajuste posológico e procedeu-se à referenciação para consulta externa de endocrinologia e oftalmologia.

Um mês depois volta a consulta na USF, sendo que apesar da estabilização da função tiroideia, se verificou progressão bilateral da exoftalmia. O seguimento e a monitorização da função tiroideia passaram a ser realizados a nível hospitalar pela especialidade de endocrinologia. Nesse âmbito foram discutidas as abordagens terapêuticas disponíveis na redução da síntese de hormonas tiroideias (tionamidas, iodo radioativo ou cirurgia) e foi decidido, em conjunto com a doente, que a tiroidectomia total seria a melhor opção no seu caso, dado apresentar um bócio de grandes dimensões. A intervenção cirúrgica decorreu sem intercorrências, tendo resultado em melhoria ligeira da acuidade visual, o que contribuiu para a redução da ansiedade da doente, já que a consulta de oftalmologia apenas estava agendada para quatro meses depois. Foi suplementada com levotiroxina, mantendo função tiroideia estável. 
Cerca de cinco meses após a primeira consulta na USF, a doente foi observada por oftalmologia. Apesar de ter sido instituído tratamento com metilprednisolona intravenosa diária verificou-se manutenção da exoftalmia, sobretudo ao nível do olho esquerdo, com persistência de diplopia e visão turva, pelo que o seu caso foi apresentado em consulta de doenças autoimunes e posteriormente proposta para plasmaferese. Foi igualmente encaminhada para consulta de oftalmo-plástica para se ponderar tratamento cirúrgico (orbitotomia descompressiva).

Neste período, a doente desenvolveu um quadro de insatisfação marcada com a modificação da sua autoimagem corporal, resultante sobretudo da exoftalmia, mas também da cicatriz de tiroidectomia. Referia que era incapaz de retirar os óculos de sol, mesmo em casa e de olhar-se ao espelho; apresentava diminuição da autoestima associada a insónia inicial e de manutenção, humor deprimido, choro fácil, irritabilidade, perda de interesse na maioria das atividades e alteração da identidade (antes e após o diagnóstico), com mais de um mês de evolução e agravado nos últimos 15 dias. A doente negava sintomatologia heteróloga, assim como ideias relacionadas com a morte ou ideação suicida. Nesta altura foi observada ao nível dos cuidados de saúde primários, onde pôde abertamente esclarecer as suas dúvidas e partilhar os medos, verbalizando angústia relativamente ao futuro, sobretudo porque os médicos não lhe davam certezas quanto à possibilidade de reversão total da exoftalmia; referia ainda medo da cegueira e incapacidade permanente dela resultante. Os autores tentaram responder às emoções e perguntas da doente, mostrando apoio e compreensão e validando a reação emocional perante as circunstâncias; procuraram diminuir a carga emocional atribuída à possibilidade de cegueira, explicando que esta se tratava de uma complicação rara e relembrando que a doente estava proposta para cirurgia de descompressão. Após caracterização da depressão nos seus níveis psicológico, social e físico foi elaborado, em conjunto com a doente, um plano de tratamento com recurso a sertralina 100mg e estímulo à criação de uma rede de suporte familiar e social eficaz; foram ainda trabalhadas estratégias de coping e pedida colaboração de psicologia. A doente foi aconselhada a manter a vigilância de alterações de humor, pensamentos negativos ou re- lacionados com morte, assim como de ideação suicida e aconselhada a procurar ajuda se algum desses sinais se agravasse ou surgisse de novo. Apesar da associação entre a oftalmopatia de Graves e o tabagismo, a consulta de cessação tabágica foi protelada até estabilização do humor. Foi agendada consulta de reavaliação em quatro semanas, onde se constatou adesão ao plano terapêutico proposto, com melhoria ligeira da sintomatologia depressiva.

Algumas semanas depois, o quadro depressivo foi agravado pela descoberta pela utente de suposta infidelidade matrimonial por parte do marido, o que viria semanas mais tarde a culminar no início de um processo de divórcio. Para além disso, nesta fase, a doente não se sentia capaz de tomar conta dos filhos, devido à sintomatologia depressiva e ao impacto severo da sintomatologia visual nas atividades de vida diárias, pelo que estes ficaram entregues ao pai. Este facto condicionou sentimentos de ambivalência na doente: afetuosidade maternal versus tentativa de proteção dos filhos do seu humor deprimido e imagem corporal alterada, acrescendo ainda o facto das crianças se encontrarem ao cuidado do pai, do qual se tinha acabado de separar. Dada a sucessão de acontecimentos negativos, a doente optou por se mudar temporariamente para casa dos pais, onde coabitou apenas com a mãe, dado que o pai se encontra emigrado. A decisão de coabitação com a mãe prendeu-se sobretudo com motivos económicos e emocionais, mas também pela incapacidade resultante dos sintomas oculares. Recebia visitas regulares da irmã e filhos. Contudo, durante este período verificou-se um agravamento da perceção da severidade da patologia pela doente, objetivada nas consultas de seguimento, assim como redução da autoestima e isolamento social. A situação clínica da doente poderá ter sido agravada pela ausência do pai, antecedentes de depressão da mãe e ainda pelo facto de, apesar de considerar a mãe um grande apoio, referir que esta não compreendia o impacto da doença no seu dia-a-dia, assim como o contexto do seu divórcio, mantendo contacto próximo com o seu ex-marido, fator de grande angústia na utente. Por outro lado, referia grande frustração por se encontrar impossibilitada de desempenhar as suas atividades laborais como cabeleireira, que nesta fase a poderiam ajudar pelo menos a manter-se ocupada. 


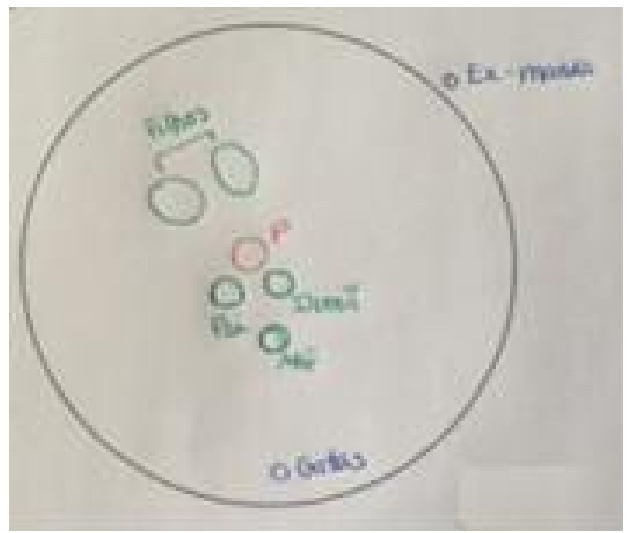

Figura 3. Círculo familiar de Thrower em 26/02/2015.

A doente foi submetida a cirurgia de descompressão por oftalmologia, com melhoria apenas parcial da exoftalmia e dos sintomas de diplopia e visão turva. Neste contexto, apesar das tentativas dos autores e da psicóloga em manter contacto regular com a doente, esta começou a faltar às consultas de seguimento, inicialmente apenas a nível hospitalar, mas posteriormente também às da USF e de psicologia. Foi tentado contacto telefónico com a utente, sem sucesso. Posteriormente, os autores tiveram conhecimento (através da nota de alta de psiquiatria) que a utente tinha suspendido o tratamento com antidepressivo, o que culminou em tentativa de suicídio por intoxicação medicamentosa e internamento num hospital psiquiátrico durante oito dias. Teve alta medicada com escitalopram $20 \mathrm{mg}$ ao pequeno-almoço, lorazepam $1 \mathrm{mg}$ e trazodona $100 \mathrm{mg}$ ao deitar, sendo que a mãe e irmã foram contactadas para que mantivessem vigilância e cuidados à doente diariamente, durante as 24 horas. Após a alta foi agendada consulta de crise por psiquiatria, assim como consultas de reavaliação quinzenais de psiquiatria e psicologia. Ao nível dos cuidados de saúde primários foram igualmente agendadas consultas de reavaliação regulares da doente, assim como dos filhos. Foi reforçada a necessidade do cumprimento terapêutico e de manutenção de seguimento multidisciplinar por psicologia e psiquiatria, sendo que foi também necessário criar e estabelecer uma articulação entre a medicina geral $\mathrm{e}$ familiar, a psicologia e a psiquiatria. Foi ainda dada especial atenção ao aconselhamento, escuta terapêutica e empática, assim como à avaliação familiar. Durante esta avaliação constatou-se que o diagnóstico e o im- pacto da oftalmopatia de Graves, associados à transformação da estrutura familiar pré-existente, constituíram uma experiência dolorosa para a doente, a qual vive num turbilhão de sentimentos de injustiça, raiva, traição e ressentimento. De acordo com a escala de $\mathrm{Hol}$ mes e Rahe, o divórcio e a separação conjugal constituem acontecimentos geradores de stress, sendo responsáveis pela destruição da estrutura familiar preexistente e têm enorme impacto sobre os dois cônjuges e sobre os filhos do casal. Assim, constatou-se também, em consultas de seguimento de saúde infantil, que os filhos poderiam estar a vivenciar sentimentos de abandono por parte da mãe por ainda não apresentarem maturidade suficiente para compreender a situação. Neste contexto foi discutido com os pais a importância de estarem atentos a possíveis sentimentos de culpabilidade, que são habituais nas crianças por frequentemente se acharem responsáveis pela separação dos pais e ainda a queixas psicossomáticas, terrores noturnos e comportamentos regressivos, dado que constituem muitas vezes formas de manifestação de tristeza pelas crianças no contexto de divórcio. Foi também proposta à doente a explicação sumária dos motivos de separação de forma adequada à idade dos filhos, o que poderia tranquilizá-los.

Foi aplicado o círculo de Thrower (Figura 3) pela importância de avaliação da dinâmica familiar e rede de suporte afetivo nesta etapa da vida da doente. Da aplicação do círculo destaca-se, em primeiro lugar, a representação inicial dos círculos de tamanho idêntico a representar os pais e a irmã mais perto de si e, em segundo lugar, a representação dos filhos, em círculos de maior tamanho, pelo seu maior significado emocional, mas mais distanciados pela incapacidade temporária de tomar conta destes; a proximidade, na representação da mãe, prendia-se sobretudo com o facto de a doente reconhecer o apoio desta e as vantagens económicas e emocionais da coabitação, admitindo que estas se sobrepunham aos sentimentos de conflituosidade. Desenhou ainda o ex-marido fora do círculo e num círculo de tamanho inferior, traduzindo a separação e conflituosidade. A doente revelou-se insatisfeita com esta representação, visto que gostaria de estar mais próxima dos filhos, declarando intenção de mudança desta situação aquando da estabilização do humor. Apesar de referir que os pais e a irmã eram o seu único 
apoio nesta fase da sua vida, atribuindo-lhes elevada importância emocional, afirmou que gostaria que o pai estivesse a residir em Portugal. A reflexão realizada pela doente acerca do círculo familiar é concordante com o resultado de disfunção moderada evidenciado no APGAR, revelando assim um fraco apoio psicossocial. A linha de vida de Medalie revela associação cronológica entre o diagnóstico de doença de Graves, divórcio e patologia depressiva, sendo esta última reativa à sucessão de acontecimentos negativos despoletados pelo diagnóstico. Por outro lado, não se pode também excluir o papel do stress emocional e crise despoletada pelo diagnóstico no agravamento da evolução e prognóstico da oftalmopatia.

Durante a avaliação foi possível identificar os recursos familiares que, apesar de escassos, constituíram importantes fontes de suporte emocional e motivação. Constatou-se também que o regresso a casa dos pais, apesar dos motivos económicos, poderá ter constituído uma regressão potencialmente útil de forma transitória. Foi realizado aconselhamento, tanto individual como familiar, em articulação com a psiquiatria e a psicologia para uma melhor gestão dos problemas recentes e promoção da resiliência. O pai regressou temporariamente a Portugal para apoiar a filha e a mãe compreendeu melhor a dinâmica do divórcio, melhorando a conflituosidade existente entre as duas. Foi ainda reforçada a necessidade de distinção entre o conflito conjugal e o papel parental e trabalhou-se o luto da separação e dos projetos conjugais, tendo a doente reconhecido a importância da comunicação intrafamiliar na partilha dos acontecimentos vitais por forma a encontrarem estratégias para partilhar e superar o luto.

Nesta fase, os cuidados de saúde primários desempenharam um papel fulcral na promoção do apoio psicossocial, sobretudo familiar, sendo que foram desenvolvidas abordagens psicoterapêuticas com técnicas simples orientadas para a resolução de problemas, oferecendo-se ainda estratégias para enfrentar períodos de maior medo e ansiedade como, por exemplo, a frequência de grupos de relaxamento, com boa adesão por parte da doente.

\section{COMENTÁRIO}

O diagnóstico de hipertiroidismo clínico é confirmado por um valor de TSH abaixo do valor de referên- cia, associado a um valor elevado de tiroxina livre (T4 livre). Nos estadios mais precoces poderá verificar-se apenas uma elevação de triiodotironina (T3), sem alterações dos níveis de T4 livre. Assim, perante a suspeita clínica, o doseamento de T3 livre deve ser efetuado em doentes com níveis de TSH reduzidos, mas níveis de T4 livre dentro dos limites da normalidade. ${ }^{2} \mathrm{O}$ doseamento de autoanticorpos antirrecetores de TSH, particularmente dos estimulantes, é quase sempre positivo, sendo a sua deteção diagnóstica de doença de Graves. ${ }^{2}$ Embora os anticorpos estimulantes da tiroide sejam os responsáveis pelo hipertiroidismo na doença de Graves, a sua concentração sérica é muito baixa e, por isso, indetetável em alguns indivíduos. ${ }^{2}$ Perante um caso semelhante ao supracitado, os cuidados de saúde primários desempenham um papel fulcral no diagnóstico inicial e orientação atempada da patologia para os cuidados de saúde secundários.

Os principais sinais e sintomas da oftalmopatia de Graves são edema palpebral, hiperemia conjuntival, prurido, lacrimejo excessivo, proptose/exoftalmia, fotofobia e dificuldade na amplitude de movimentos oculares, a que pode associar-se a dor à mobilização. ${ }^{2} \mathrm{~A}$ exoftalmia ocorre em até um terço dos doentes, podendo ser assimétrica e parcialmente mascarada pelo edema peri-orbitário; a diplopia ocorre em 5 a $10 \%$ dos casos. $^{2} \mathrm{O}$ exame objetivo deve incluir a inspeção da conjuntiva e tecido periorbitário, com vista à identificação de sinais como hiperemia conjuntival e edema periorbitário e falha na aposição da pálpebra superior e inferior; deve também proceder-se à avaliação dos movimentos oculares, acuidade visual e visão cromática. ${ }^{2}$ A correlação entre os sintomas e os sinais de oftalmopatia de Graves é muitas vezes escassa. Os achados ao exame objetivo são importantes para o prognóstico e tratamento, mas é igualmente importante a perceção do doente acerca da sua sintomatologia, assim como a alteração desta. ${ }^{4,7} \mathrm{O}$ questionário Graves Ophthalmopathy Quality of Life Questionnaire (GO-QoL) é uma ferramenta validada que pode ser utilizada na avaliação das mudanças na função visual e na aparência percecionadas pelos pacientes com oftalmopatia de Graves, sendo constituída por oito perguntas sobre as consequências da diplopia e diminuição da acuidade visual e oito perguntas sobre as consequências psicológicas devido às alterações da aparência. ${ }^{715}$ No caso clínico 
descrito, este questionário poderia ter sido aplicado inicialmente e após a intervenção cirúrgica de forma a objetivar o impacto das alterações visuais e da aparência na qualidade de vida da doente.

Nestes casos deve ser dada atenção à prevenção secundária, através do controlo do hipotiroidismo e dos fatores de risco associados à patologia em questão, partilhando informação sobre as consequências de comportamentos de risco. ${ }^{16}$ Neste nível de prevenção, a cessação tabágica é a principal medida a propor aos pacientes com doença de Graves, o mais precocemente possível. No caso descrito foi protelada a intervenção na cessação tabágica devido ao humor depressivo da doente; contudo, poderia ter sido importante o início precoce do aconselhamento com recurso a uma intervenção breve, aquando do diagnóstico, altura em que a sintomatologia depressiva ainda não estava presente. Se a doente nesta fase não estivesse motivada, poderia ter-se investido numa intervenção motivacional, com escuta reflexiva e enfoque nos riscos imediatos e a longo prazo decorrentes da manutenção deste hábito no prognóstico da patologia em questão. Em retrospetiva, os autores pretendem alertar e reforçar a importância desta medida, com implicações prognósticas, de acordo com as recomendações da European Group on Graves Orbitopathy 2016. ${ }^{17}$ Contudo, realçam também que, apesar da associação estabelecida entre o tabagismo e a severidade da oftalmopatia, a evidência da cessação tabágica na melhoria dos outcomes relacionados com a exoftalmia e a diplopia é baseada apenas num estudo retrospetivo de 1996, sendo por isso escassa. $^{18}$

Apesar da referenciação precoce com descrição da gravidade do quadro, a consulta de oftalmologia foi agendada apenas para cinco meses depois. Esta situação poderia ter sido notificada ao presidente do Conselho Clínico, para articulação com o chefe de serviço de oftalmologia do hospital de referência, sendo que os autores pretendem chamar a atenção para futuras situações semelhantes. Durante o tempo de espera, o médico de família poderá desempenhar um papel importante na prevenção terciária, com vista à redução das complicações e incapacidade imputada pela doença e adaptação do doente à vivência com a patologia. ${ }^{16}$ O recurso a medidas simples, como óculos escuros e lágrima artificial durante o dia, elevação da cabeça no lei- to e uso de lubrificante à noite, alivia os sintomas na maioria dos doentes e pode prevenir complicações decorrentes da oftalmopatia. ${ }^{2}$

A morbilidade psicossocial é comum nos indivíduos com oftalmopatia de Graves. As perturbações na função visual, proptose desfigurativa e sintomas associados, nomeadamente a diplopia, aliados à modificação da imagem corporal, são os principais contribuintes para a disfunção psicológica nesta condição. ${ }^{4,13} \mathrm{O}$ nível pré-mórbido de funcionalidade física, psicológica e social do indivíduo, assim como a intensidade da perceção dos sintomas e mecanismos de coping, constituem fatores relevantes adicionais que podem determinar a magnitude do impacto psicológico da oftalmopatia. ${ }^{13}$ Os quadros graves de oftalmopatia de Graves, apesar de pouco frequentes, estão associados a uma elevada morbilidade psicossocial, com um impacto marcado no estado funcional e bem-estar do paciente, para o qual o médico de família deve estar sensibilizado. ${ }^{4}$ As terapêuticas habituais são primariamente direcionadas para a melhoria da função visual e aparência, mas adicionalmente é fundamental direcionar o foco para a melhoria do funcionamento psicossocial dos doentes, tanto pelo impacto da doença física nas alterações emocionais, como pelo impacto emocional no controlo e prognóstico da patologia. ${ }^{7} \mathrm{O}$ presente caso demonstra que a doente não estava apenas fisicamente doente, mas também apresentava distress psicológico associado às alterações visuais, que eram responsáveis por um impacto severo no seu funcionamento diário. O diagnóstico associou-se a um quadro de insatisfação marcada com a sua autoimagem corporal e diminuição da autoestima, assim como a uma série de eventos negativos, como o divórcio e a impossibilidade de tomar conta dos filhos, que culminou em depressão com tentativa de suicídio. Como anteriormente referido, a depressão é frequente em doentes com oftalmopatia de Graves, sendo que a doente apresentava múltiplos fatores de risco para suicídio, nomeadamente doença física com limitação funcional e alteração da imagem corporal, depressão e elevados níveis de desesperança. ${ }^{14}$ Os cuidados de saúde primários estão bem posicionados no acompanhamento da dimensão biopsicossocial e na mobilização de recursos, sendo fulcral a existência de uma relação médico-paciente de confiança e partilha. A comunicação como a técnica primordial 
para o atingimento dos objetivos, a escuta terapêutica e empática, aliada à demonstração de disponibilidade e proximidade para que os pacientes possam abertamente esclarecer as suas dúvidas e partilharem os seus medos relacionados com a progressão da doença e implicações futuras, podem contribuir para a melhoria da autoestima e para a diminuição da ansiedade e depressão associadas à oftalmopatia de Graves, permitindo melhorar a qualidade de vida dos doentes. A articulação com a medicina do trabalho pode também ser importante na adaptação do local de trabalho. Por outro lado, o papel do médico de família como gestor de cuidados permite a integração e articulação entre os diferentes níveis de cuidados que envolvem a abordagem desta patologia, nomeadamente a endocrinologia, a oftalmologia, a psicologia e, eventualmente, a psiquiatria. Assim, os autores pretendem sensibilizar os médicos de família na gestão de doença orgânica, bem como das suas consequências sociais e psiquiátricas.

O sucesso do tratamento depende também do entendimento da dinâmica familiar e da função que a doença assume na família e na vida do doente, motivo pelo qual foi realizada a avaliação familiar. O envolvimento da família no tratamento de todas as manifestações da doença é fulcral, tornando as intervenções mais efetivas e aumentando os recursos de auxílio ao doente, sobretudo no que respeita a adesão terapêutica. Por outro lado, ajudar as famílias a lidar melhor com o stress da doença, através da mobilização do suporte emocional da família, com aproximação dos membros, pode reduzir os efeitos negativos do trauma relacionado com a doença. Em famílias com poucos recursos de apoio, como no caso apresentado, o médico de família poderá mesmo ter um papel fundamental na resolução da crise. ${ }^{19}$ Neste caso poderia ter sido útil a insistência no contacto telefónico com a doente quando começou a faltar às consultas de seguimento na USF ou mesmo o contacto com outros elementos da família.

Em suma, os cuidados de saúde primários constituem o primeiro ponto de contacto com o sistema nacional de saúde, pelo que ocupam uma posição privilegiada na deteção dos sintomas e sinais da doença de Graves. A deteção e a avaliação clínica inicial desta patologia estão ao alcance dos médicos de família, referenciando os casos detetados aos cuidados de saúde secundários. Apesar desta referenciação, o médico de fa- mília é responsável pelo seguimento longitudinal dos doentes, desempenhando um papel fulcral na gestão e na articulação dos múltiplos intervenientes no processo de controlo destas patologias, sobretudo pelo impacto negativo ao nível psicológico, social e laboral e pela afetação da qualidade de vida.

\section{REFERÊNCIAS BIBLIOGRÁFICAS}

1. Brent GA. Clinical practice: Graves' disease. N Engl J Med. 2008;358(24): 2594-605.

2. Neves C, Alves M, Delgado JL, Medina JL. Doença de Graves [Graves' disease]. Arq Med. 2008;22(4-5):137-46. Portuguese

3. Weetman AP. Graves' disease. N Engl J Med. 2000;343(17):1236-48.

4. Estcourt S, Vaidya B, Quinn A, Shepherd M. The impact of thyroid eye disease upon patients' wellbeing: a qualitative analysis. Clin Endocrinol. 2008;68(4):635-9.

5. Lazarus JH. Epidemiology of Graves' orbitopathy (GO) and relationship with thyroid disease. Best Pract Res Clin Endocrinol Metab. 2012; 26(3):273-9.

6. Burch HB, Wartofsky L. Graves' ophthalmopathy: current concepts regarding pathogenesis and management. Endocr Rev. 1993;14(6): 747-93.

7. Terwee CB, Dekker FW, Prummel MF, Wiersinga WM. Graves' ophthalmopathy through the eyes of the patient: a state of the art on healthrelated quality of life assessment. Orbit. 2001;20(4):281-90.

8. Prummel MF, Wiersinga WM. Smoking and risk of Graves' disease. JAMA. 1993;269(4):479-82.

9. Eckstein AK, Plicht M, Lax H, Neuhäuser M, Mann K, Lederbogen S, et al. Thyrotropin receptor autoantibodies are independent risk factors for Graves' ophthalmopathy and help to predict severity and outcome of the disease. J Clin Endocrinol Metab. 2006;91(9):3464-70.

10. Martín-Merino E, Ruigómez A, Johansson S, Wallander MA, García-Rodríguez LA. Study of a cohort of patients newly diagnosed with depression in general practice: prevalence, incidence, comorbidity, and treatment patterns. Prim Care Companion J Clin Psychiatry. 2010;12(1): e1-e8.

11. Brandt F, Thvilum M, Almind D, Christensen $K$, Green A, Hegedüs $L$, et al. Hyperthyroidism and psychiatric morbidity: evidence from a Danish nationwide register study. Eur J Endocrinol. 2013;170(2):341-8.

12. Gulseren S, Gulseren L, Hekimsoy Z, Cetinay P, Ozen C, Tokatlioglu B. Depression, anxiety, health-related quality of life, and disability in patients with overt and subclinical thyroid dysfunction. Arch Med Res. 2006;37(1):133-9.

13. Coulter I, Frewin S, Krassas GE, Perros P. Psychological implications of Graves' orbitopathy. Eur J Endocrinol. 2007;157(2):127-31.

14. Direção-Geral da Saúde. Plano nacional de prevenção do suicídio, 20132017. Lisboa: DGS; 2017.

15. Terwee CB, Dekker FW, Mourits MP, Gerding MN, Baldeschi L, Kalmann $R$, et al. Interpretation and validity of changes in scores on the Graves' ophthalmopathy quality of life questionnaire (GO-QOL) after different treatments. Clin Endocrinol. 2001;54(3):391-8.

16. Bartalena L. Prevention of Graves' ophthalmopathy. Best Pract Res Clin Endocrinol Metab. 2012;26(3):371-9. 
17. Bartalena L, Baldeschi L, Boboridis K, Eckstein A, Kahaly GJ, Marcocci C, et al. The 2016 European Thyroid Association/European Group on Graves' Orbitopathy Guidelines for the Management of Graves' Orbitopathy. Eur Thyroid J. 2016;5(1):9-26.

18. Pfeilschifter J, Ziegler R. Smoking and endocrine ophthalmopathy: impact of smoking severity and current vs lifetime cigarette consumption. Clin Endocrinol. 1996;45(4):477-81.

19. Rebelo L, editor.A família em medicina geral e familiar: conceitos e práticas. Coimbra: Almedina; 2018. ISBN 9789724073132

\section{CONFLITO DE INTERESSES}

Os autores declaram não possuir quaisquer conflitos de interesse.

\section{FINANCIAMENTO}

Os autores declaram não ter recorrido a qualquer financiamento para a conclusão deste artigo.

\author{
ENDEREÇO PARA CORRESPONDÊNCIA \\ Ana Cláudia Cardoso Almeida \\ E-mail: claudia.ac.almeida@gmail.com \\ http://orcid.org/0000-0002-1561-9362
}

Recebido em 12-09-2016

Aceite para publicação em 30-06-2018

\begin{abstract}
GRAVES' DISEASE: THE PATIENT'S VIEW AND BIOPSYCHOSOCIAL IMPACT - A CASE REPORT

Introduction: This case intends to emphasize the importance of the role of the family physician, not only in the clinical suspicion of Graves' disease and associated complications, but also in the adaptation to living with the disease, given the psychosocial morbidity associated with disfiguring proptosis and/or diplopia, both of which have a marked impact on the functional status and well-being of patients.

Case report: A 29 year-old female, with irrelevant pathological history, was diagnosed with Graves' disease, with associated ophthalmopathy causing retro-ocular pain and diplopia, which significantly affected her daily life. Despite stabilization of thyroid function with the treatment, bilateral exophthalmia progressed. In this context, she developed dissatisfaction with her body image, altered identity (before and after the diagnosis), and depression, culminating in a suicide attempt by drug intoxication. Discussion: Family physicians should be aware of the negative impact on mental and physical health, social and economic skills, and on the quality of life of these patients. In this case, the patient was not only physically ill, but also presented psychological distress due to Grave's ophtalmopathy, which were responsible for a severe impact on her daily living.
\end{abstract}

Keywords: Graves' disease; Grave's ophtalmopathy; Quality of life; Exophthalmos; Hyperthyroidism. 